\title{
The Development and Psychometric Validation of an Arabic-Language Version of the Pain Catastrophizing Scale
}

\author{
Huda Abu-Saad Huijer, ${ }^{1}$ Souha Fares, ${ }^{1}$ and Douglas J. French ${ }^{2}$ \\ ${ }^{1}$ Hariri School of Nursing, American University of Beirut, Beirut, Lebanon \\ ${ }^{2}$ School of Psychology, Université de Moncton, Moncton, NB, Canada \\ Correspondence should be addressed to Huda Abu-Saad Huijer; huda.huijer@aub.edu.lb
}

Received 7 March 2016; Accepted 15 December 2016; Published 16 January 2017

Academic Editor: Celeste C. Johnston

Copyright (c) 2017 Huda Abu-Saad Huijer et al. This is an open access article distributed under the Creative Commons Attribution License, which permits unrestricted use, distribution, and reproduction in any medium, provided the original work is properly cited.

\begin{abstract}
Context. The Pain Catastrophizing Scale (PCS) is the most widely used measure of pain-specific catastrophizing. Objectives. The purpose of the present study was to develop and psychometrically evaluate an Arabic-language version of the PCS. Methods. In Study 1, 150 adult chronic nonmalignant pain patients seeking treatment at a hospital setting completed the PCS-A and a number of self-report measures assessing clinical parameters of pain, symptoms of depression, and quality of life. Study 2 employed a cold pressor pain task to examine the PCS-A in a sample of 44 healthy university students. Results. Exploratory factor analyses suggested a two-factor structure. Confirmatory factor analysis comparing the 2-factor model, Sullivan's original 3-factor model, and a 1-factor model based on the total score all provided adequate fit to the data. Cronbach's alpha coefficients across all models met or exceeded accepted standards of reliability. Catastrophizing was associated with higher levels of depression and increased pain intensity and interference. Catastrophizing predicted decreased quality of life, even after controlling for the contribution of gender, employment, depression, and pain interference. PCS-A scores were positively correlated with heightened experimental pain severity and decreased pain tolerance. Conclusion. The present results provide strong support for the psychometric properties of the PCS-A.
\end{abstract}

\section{Introduction}

Pain catastrophizing is characterized as the tendency to magnify the level of threat associated with perceived or anticipated pain, to feel helpless in the face of pain, and to focus excessively on pain sensations $[1,2]$. This negative "mental set" has repeatedly been shown to be one of the most robust and reliable psychological predictors of the overall pain experience in experimental studies of pain [1-6] and in individuals undergoing acutely painful medical treatments and procedures [7-10]. Numerous studies of individuals with persistent clinical pain have also found catastrophizing to relate to a number of pain-related outcomes including pain severity, disability, activity interference, quality of life, and health care utilization [11-15]. Furthermore, treatment outcome studies have demonstrated that high levels of pain catastrophizing are associated with poor responses to pharmacological intervention [16], surgical treatment [17], physical therapies $[18,19]$, and psychological interventions for pain conditions [20].

As one of the most widely used measures of catastrophic thinking related to pain, the PCS has been repeatedly shown to be a valid and reliable tool for assessing pain catastrophizing. This measure is brief and may be easily integrated into existing assessment protocols with little increase in patient burden. The multidimensional nature of the PCS is also useful for tailoring clinical interventions to an individual's specific profile. It has been validated in more than 22 languages worldwide [4, 21-28] yet an Arabic-language adaptation has not been developed. The purpose of this research was to develop and psychometrically evaluate an Arabic-language version of the PCS, the PCS-A. It is hoped that the availability of an Arabic-language version will facilitate pain research and treatment in the Arab world. Two studies were conducted. Study 1 examines the factor structure of the PCS-A and the prediction of pain severity and disability in Lebanese chronic 
pain patients presenting for treatment in a hospital setting. Study 2 employs a cold pressor paradigm to examine acute pain responsiveness in university students from a number of Arab countries studying in Canada and compares state and trait levels of catastrophizing using the PCS-A. It is hoped that the availability of a validated Arabic-language PCS will contribute to the assessment and treatment of Arab pain patients and will be useful for pain researchers in Arab countries.

\section{Study 1}

\subsection{Method}

2.1.1. Setting and Subjects. One hundred and fifty $(n=150)$ adults (aged 18 years and older) with chronic nonmalignant pain were recruited from the outpatient pain clinic and the rheumatic arthritis clinics of the AUB Medical Center. Participants reported spinal pain with or without radiculopathy and local pain syndromes of the upper and lower limbs. The research assistants (RAs) approached the patients in the waiting area, introduced themselves, and informed them about the purpose of the study. If the patient agreed to participate, the informed consent was explained and the RA secured their signatures. Afterwards, the RA administered the questionnaires in a structured interview-type format.

2.1.2. Questionnaires. With the exception of the PCS-A, selfreport measures have all been previously validated in Arabic with published research demonstrating psychometric properties comparable to the original English-language versions.

2.1.3. Pain Catastrophizing Scale-Arabic Version (PCS-A). The PCS-A is an Arabic-language translation of the original 13item PCS [1]. Like the original version, the PCS-A asks respondents to reflect on past painful experiences and to indicate the degree to which they experience the thoughts or feelings described in each item when experiencing pain; for example, "I become afraid that the pain will get worse." Items are rated on a 5-point scale with end points of $(0)$ "not at all" and (4) "all the time."

2.1.4. Brief Pain Inventory (BPI)-Arabic Version. The Arabic-language adaptation of the 16-item Brief Pain Inventory (BPI) assesses clinical pain severity and the degree to which pain interferes with a number of common functional domains. In addition to a bodily pain diagram, the BPI includes four pain severity items and seven pain interference items rated on 0-10 scales. Ballout et al. [29] showed that the Arabic-language translation demonstrated cultural sensitivity and adequate psychometric properties comparable to the original version when used in a sample of Lebanese cancer patients experiencing pain.

2.1.5. European Organization for Research and Treatment of Cancer Quality of Life Questionnaire C30 (EORTC QLQC30)_Lebanese Arabic Version. The EORTC QLQ-C30 is a 30-item self-report questionnaire composed of five functional subscales (physical, role, cognitive, emotional, and social subscales), three symptom scales (fatigue, pain, nausea, and vomiting), and a global health status and quality of life scale (GHS, QoL scale). Higher scores on the functional subscales, as well as the GHS and QoL subscales, are indicative of higher levels of functioning as opposed to the symptom subscales for which higher scores are indicative of higher levels of symptom activity. The EORTC QLQ-C30 has been translated into Arabic and psychometrically validated in a large sample of Lebanese cancer patients [30].

2.1.6. CES-D Depression Scale (CES-D)-Arabic Version. The Arabic CES-D scale is a 20-item measure of depressive symptoms. Symptom ratings varied from 0 to 3 : $0=$ rarely or none of the time and $3=$ most or all of the time, 5-7 days [31]. Positive items were reverse coded and the responses were summed such that higher scores are indicative of increasing depression. The total scale score was used in the present study as recommended by Kazarian and Taher [32].

2.1.7. Translation and Pilot Testing. The PCS was translated to Arabic using the forward and backward translation method. An initial professional translation was sent to two experts in the Arabic-language for evaluation. The backward translation was carried out by an independent translator with no prior knowledge of the original version. It was then validated for cultural appropriateness by four experts in the field and then pilot tested on a small sample of patients $(n=5)$ for clarity of the items, length, and the presence of distressing items. In light of culture-specific differences in spoken and written Arabic across countries, it was our goal to develop an Arabiclanguage version that could be used widely. As such, every effort was made to ensure the PCS-A conformed to Classic Arabic norms.

2.1.8. Analysis. Statistical analyses were performed using the statistical package for the social sciences (SPSS), version 23, and STATA version 13.1 for Windows. Descriptive analyses were used to describe the characteristics of the study sample.

Exploratory Factor Analysis (EFA) was conducted to determine the factor structure of the scale. The extraction method used was principal axis factoring with oblique rotation (promax). The number of factors to be extracted was determined according to eigenvalues and the scree plot. Confirmatory factor analysis was then conducted to assess the construct validity and goodness of fit of the model revealed from the current study and to compare it to other models previously reported in the literature. The CFA goodness of fit indices used were the root mean square error of approximation (RMSEA $\leq 0.8$ ) [33], nonnormed fit index $(\mathrm{NNFI} \geq 0.9)[34]$, and comparative fit index $(\mathrm{CFI} \geq 0.9)$ $[30,32]$.

Construct validity was also examined by correlating (Pearson's $r$ ) the PCS-A score with depression, pain severity, pain interference, and quality of life scores. The knowngroups technique was used to compare PCS-A scores between demographic subgroups ( $t$-tests). The ability of the PCS-A to 
predict quality of life (QoL subscale of the EORTC QLQC-30) while controlling for pain, psychosocial characteristics, and demographic variables was tested by multiple hierarchical regression analysis.

The internal consistency of the original and resulting factors was examined using Cronbach's alpha $(\alpha)$, Cronbach's alpha if item deleted, interitem correlations, and corrected item-total correlations.

\subsection{Results}

2.2.1. Demographic and Clinical Characteristics. The mean participant age was 49.03 years $(\mathrm{SD}=13.99)$. The majority were female $(67 \%)$, completed secondary education $(35 \%)$, were currently married (73\%), were unemployed (55\%), and had been experiencing pain for more than six months (61\%). Approximately 39\% of the participants had low back pain and $26 \%$ reported pain in the ankle/foot and $25.3 \%$ in the wrist/hand.

2.2.2. Exploratory Factor Analysis. When examining the EFA results, only the first factor had an eigenvalue greater than one, equal to 9.69 accounting for $74.55 \%$ of the total variance. This provides strong evidence on the unidimensionality of the PCS-A. The scree plot however showed two points above "the elbow," which led us to assess the two-factor structure later using CFA. When forced into the EFA, the two factors accounted for $80 \%$ of the total variance. Factor 1 included items 1-5 and item 12 which corresponds to the "Helplessness" subscale reported with the original scale [1]. Factor 2 included the remaining items $6-11$ and 13, thus grouping the "Rumination" and "Magnification" factors in the original study and this was labelled Rumination/Magnification factor. All factor loadings were $>0.4$ and no items loaded on both factors (Table 1).

2.2.3. Confirmatory Factor Analysis. The goodness of fit of the two-factor oblique solution suggested by EFA was assessed and compared to the one-factor model including all thirteen items also suggested by EFA and the oblique three-factor model proposed by Sullivan et al. [1]. The two-factor model showed good fit with CFI $>0.9$ and NNFI $>0.9$ while RMSEA $=0.11>0.08$ which still indicates an acceptable fit. The fit of the original three-factor model was also acceptable and identical to the two-factor model. The one-factor model also showed adequate fit but was slightly poorer than the other two. The CFA indices are summarized in Table 2.

2.2.4. Reliability. Within the two-factor model, values of Cronbach's alpha were well above the standard of reliability with a coefficient of 0.97 for the total score, 0.96 for factor 1 , and 0.95 for factor 2. These values are all comparable to or higher than values obtained for three subscales when created according to Sullivan's item groupings. All corrected itemtotal correlations were high ranging from 0.76 to 0.90 for the one-factor model and from 0.82 to 0.90 for the Rumination/Magnification dimension in the two-factor model and from 0.76 to 0.90 for the Helplessness dimension.
TABLE 1: EFA using principle axis factoring and promax rotation.

\begin{tabular}{lcc}
\hline Items & \multicolumn{2}{c}{ Factors } \\
\hline $\begin{array}{l}\text { I worry all the time about whether } \\
\text { the pain will end }\end{array}$ & 0.09 & $\mathbf{0 . 7 3}$ \\
$\begin{array}{l}\text { I feel I can't go on } \\
\text { It's terrible and I think it's never }\end{array}$ & 0.11 & $\mathbf{0 . 7 7}$ \\
going to get any better & 0.22 & $\mathbf{0 . 7 3}$ \\
$\begin{array}{l}\text { It's awful and I feel that it } \\
\text { overwhelms me }\end{array}$ & 0.16 & $\mathbf{0 . 7 7}$ \\
$\begin{array}{l}\text { I feel I can't stand it anymore } \\
\text { I become afraid that the pain will }\end{array}$ & -0.04 & $\mathbf{0 . 9 8}$ \\
get worse & $\mathbf{0 . 7 3}$ & 0.15 \\
$\begin{array}{l}\text { I keep thinking of other painful } \\
\text { events }\end{array}$ & $\mathbf{0 . 9 2}$ & -0.10 \\
$\begin{array}{l}\text { I anxiously want the pain to go away } \\
\text { I can't seem to keep it out of my } \\
\text { mind }\end{array}$ & $\mathbf{0 . 7 1}$ & 0.15 \\
$\begin{array}{l}\text { I keep thinking about how much it } \\
\text { hurts }\end{array}$ & $\mathbf{0 . 7 8}$ & 0.15 \\
$\begin{array}{l}\text { I keep thinking about how badly I } \\
\text { want the pain to stop }\end{array}$ & $\mathbf{0 . 6 8}$ & 0.28 \\
$\begin{array}{l}\text { There's nothing I can do to reduce } \\
\text { the intensity of the pain }\end{array}$ & $\mathbf{0 . 7 2}$ & 0.23 \\
$\begin{array}{l}\text { I wonder whether something } \\
\text { serious may happen }\end{array}$ & 0.35 & $\mathbf{0 . 4 8}$ \\
\hline
\end{tabular}

2.2.5. Concurrent and Predictive Validity. PCS-A scores were significantly higher in females $(\mathrm{M}=28.6, \mathrm{SD}=14.3)$ compared to males $(\mathrm{M}=20.2 \mathrm{SD}=12.8 ; t(141)=-3.44$, $p=0.001)$. PCS-A scores were positively correlated with depression scores $(r=0.55, p<0.001)$ and negatively correlated with quality of life scores $(r=-0.45, p<0.001)$, physical functioning $(r=-0.46, p<0.001)$, emotional functioning $(r=-0.55, p<0.001)$, and role functioning $(r=-0.47, p<0.001)$ scores. The correlations with pain interference and pain severity were also significant $(r=0.37$, $p<0.001$ and $r=0.26, p=0.002$ ).

The predictive validity of the PCS-A was assessed using multiple hierarchical linear regression (Table 3 ). Variables significantly associated with quality of life at the univariate level were entered as follows: in the first step, demographic characteristics were entered; in the next step pain and psychosocial variables were entered followed by PCS-A score in the last step. Quality of life was predicted by PCS-A scores even after controlling for gender, employment, depression, and pain interference $(B=-0.36,95 \%$ CI from -0.64 to -0.09 , and $p$ value $<0.05)$.

\section{Study 2}

3.1. Participants. A sample of forty-four $(n=44 ; 13$ females, 31 males) Arab-speaking international students attending a French-Canadian university were recruited by posters placed on campus billboards and via mass email recruitment drives. Participants were young adults (mean age in years $=24.2$, 
TABLE 2: Goodness of fit indices of the different used models.

\begin{tabular}{lcccc}
\hline & & RSMEA & CFI & NNFI \\
\hline Model 1 & One factor (13 items) & 0.15 & 0.90 & 0.88 \\
Model 2 & Two oblique factors (7 +6 items) & 0.11 & 0.95 & 0.94 \\
Model 3 & Three oblique factors (6 + 3 + 4 items) & 0.11 & 0.95 & 0.94 \\
\hline
\end{tabular}

Model 2 revealed by the current study and Model 3 suggested by Sullivan et al. [1].

TABLE 3: Summary of hierarchical regression analysis for PCS-A predicting quality of life (QoL).

\begin{tabular}{|c|c|c|c|c|c|c|c|c|c|}
\hline \multirow{2}{*}{ Variable } & \multicolumn{3}{|c|}{ Step 1} & \multicolumn{3}{|c|}{ Step 2} & \multicolumn{3}{|c|}{ Step 3} \\
\hline & $B$ & $\mathrm{SE}(B)$ & $\mathrm{CI}$ & $B$ & $\operatorname{SE}(B)$ & $\mathrm{CI}$ & $B$ & $\mathrm{SE}(B)$ & $\mathrm{CI}$ \\
\hline Gender & -1.42 & 4.65 & $(-10.62 ; 7.78)$ & 2.05 & 4.04 & $(-5.95 ; 10.05)$ & 3.45 & 3.98 & $(-4.43 ; 11.33)$ \\
\hline Employment & $11.09^{*}$ & 4.34 & $(2.49 ; 19.69)$ & $8.12^{*}$ & 4.03 & $(0.14 ; 16.10)$ & 7.30 & 3.95 & $(-0.52 ; 15.12)$ \\
\hline CES-D & & & & $-0.41^{*}$ & 0.20 & $(-0.80 ;-0.01)$ & -0.21 & 0.21 & $(-0.62 ; 0.20)$ \\
\hline Pain interference & & & & $-3.18^{*}$ & 0.89 & $(-4.94 ;-1.41)$ & $-3.01^{*}$ & 0.88 & $(-4.74 ;-1.28)$ \\
\hline PCS-A & & & & & & & $-0.36^{*}$ & 0.14 & $(-0.64 ;-0.09)$ \\
\hline Adjusted $R^{2}$ & 0.05 & & & 0.32 & & & 0.36 & & \\
\hline$\Delta R^{2}$ & $0.07^{*}$ & & & $0.25^{*}$ & & & $0.04^{*}$ & & \\
\hline
\end{tabular}

${ }^{*} p<0.05$.

$\mathrm{SD}=5.7$ ) from Morocco (50\%), Tunisia (38.6\%), Algeria (9.1\%), and Lebanon (2.3\%).

\subsection{Measures and Apparatus}

3.2.1. Pain Catastrophizing Scale-Arabic Version (PCS-A). The PCS-A represented the Arabic-language translation of the original PCS [1]. Like the original version, the PCS-A consisted of 13 items describing different thoughts and feelings that individuals may experience when they are in pain. The PCS-A and a modified version which asks participants to reflect on thoughts and feelings they experienced during the experimental pain task (state catastrophizing) were employed.

3.2.2. Spielberger State Anxiety Inventory (STAI). The STAI consists of two 20 -item subscales comprised of 20 short statements reflecting cognitive symptoms of anxiety. Participants are asked to rate how they feel either at the moment (State Anxiety) or in general (Trait Anxiety) on a four-point scale, from 1 (not at all) to 4 (very much so). This scale is widely used as a research tool and has demonstrated acceptable internal consistency, test-retest reliability, and construct validity [35].

3.2.3. Numeric Rating Scale (NRS). This scale comprises a vertical line graphic labelled with intensity-denoting adjectives and numbers ranging from 0 (no pain) to 100 (maximum tolerable pain). These rating scales are widely used measures of subjective pain and have been shown to possess adequate reliability and validity [36].

3.2.4. Cold Pressor (Wine Well Chiller Co., Inc.) The Model II-BX consists of a refrigerated tank with a $30 \mathrm{~cm}$ diameter opening that constantly circulates and maintains 40 liters of water at an average temperature of $2 \pm 0.5^{\circ} \mathrm{C}$.
3.3. Method. Participants began by completing the PCS-A and the STAI. The $0-100$ numeric rating scale (NRS) was explained to participants prior to the cold pressor test which proceeded in the following manner: participants were instructed to immerse their nondominant hand into the circulating ice water and to indicate when they first began to experience pain (threshold). They were instructed to leave their hand immersed until they could no longer tolerate the pain, at which point they could remove their hand (tolerance). Time of immersion in seconds was calculated using a stopwatch. Participants then provided an NRS rating of the overall level of pain associated with the immersion task and they completed the state version of the PCS-A.

3.4. Results. Visual inspection of study data and formal measures of skewness and kurtosis revealed that the distribution of scores on all variables did not deviate significantly from normality.

Reliability was assessed using Cronbach's alpha and interitem correlations. A high degree of internal consistency was found within both the original trait version and the modified state version of the PCS-A whether examined using the 13-item total score (range of $\alpha=0.88-0.92$; range of interitem $r=.57-.65)$ or within each the three original subscales (range of $\alpha=0.63-0.89$; range of interitem $r=$ 0.45-0.71).

As shown in Table 4, males and females did not differ significantly on PCS for both state and trait catastrophizing. Males and females did differ however on cold pressor performance with females reporting significantly lower pain threshold and tolerance times compared to their male counterparts. No significant sex differences in NRS values of overall pain severity were observed.

Table 5 presents the correlations among study variables. Consistent with previous studies, state catastrophizing (thoughts and feelings experienced during the pain task) 
TABLE 4: Means and standard deviations for study variables.

\begin{tabular}{|c|c|c|c|c|c|c|c|}
\hline & \multicolumn{2}{|c|}{ Total sample } & \multicolumn{2}{|c|}{ Males } & \multicolumn{2}{|c|}{ Females } & \multirow{2}{*}{$t$} \\
\hline & $\mathrm{M}$ & $\mathrm{SD}$ & M & SD & M & SD & \\
\hline PCS-A & 21.9 & 9.5 & 22.16 & 8.27 & 21.23 & 12.37 & -0.25 \\
\hline PCS-A state & 18.9 & 11.8 & 17.97 & 10.89 & 21.08 & 14.06 & 0.79 \\
\hline \multicolumn{8}{|l|}{ STAI $(n=19)$} \\
\hline Trait & 39.8 & 10.5 & 37.15 & 7.98 & 45.67 & 7.98 & 1.73 \\
\hline State & 31.6 & 7.6 & 29.69 & 7.55 & 35.67 & 9.07 & 1.68 \\
\hline \multicolumn{8}{|l|}{ Pain } \\
\hline Threshold & 19.2 & 12.9 & 22.10 & 14.09 & 13.15 & 7.13 & $-2.67^{* *}$ \\
\hline Tolerance & 99.3 & 88.2 & 113.20 & 94.15 & 66.09 & 63.18 & $-1.93^{* *}$ \\
\hline NRS pain & 71.9 & 18.5 & 71.23 & 18.03 & 73.46 & 20.14 & 0.36 \\
\hline
\end{tabular}

TABLE 5: Intercorrelations among study variables.

\begin{tabular}{lcccccc}
\hline Scales & $(1)$ & $(2)$ & $(3)$ & $(4)$ & $(5)$ & $(6)$ \\
\hline (1) PCS-A & - & $0,54^{* *}$ & 0,15 & 0,12 & $-0,09$ & $-0,30^{*}$ \\
(2) PCS-A state & & - & $-0,12$ & $-0,11$ & $-0,37^{* *}$ & $-0,53^{*}$ \\
(3) STAI trait & & & - & $0,55^{* *}$ & $-0,10$ & $-0,13$ \\
(4) STAI state & & & - & 0,15 & $-0,53^{* *}$ \\
(5) Threshold & & & & $-0,15$ \\
(6) Tolerance & & & & $-0,09$ & $-0,52^{* *}$ \\
(7) NRS Pain & & & & $-0,38^{* *}$ \\
\hline
\end{tabular}

${ }^{*} p<0.05{ }^{* *} p<0.01$.

assessed proximal to pain induction, demonstrated a stronger and a more consistent relationship across pain measures compared to ratings of participants' tendency to catastrophize in response to pain generally. Higher PCS-A scores were associated with heightened levels of experimental cold pressor pain, as suggested by lower pain thresholds, higher pain intensity ratings, and decreased pain tolerance.

\section{Discussion and Conclusion}

4.1. Factor Structure of the PCS-A. Previous studies of the validity and reliability of the PCS have yielded results that were psychometrically comparable to Sullivan's original 3-factor structure: Rumination, Magnification, and Helplessness. This factor structure, however, was not invariant across investigations. Some of the studies suggested a 3factor solution with similar item groupings [22, 28] while another suggested a 3-factor structure but with different item groupings [21]. The present data yielded a clear 2-factor structure with factor I reproducing the original Helplessness subscale [1] and factor II a combination of Magnification and Rumination. The item-loadings are different again from the results of Osman et al. [37] that previously suggested 2 factors.

Regarding the CFI results, our findings are similar to a number of previous factor analytic studies of the PCS [21, 38-40] and accounted for a greater percentage of variance compared to the others $[33,34]$. Our NNFI findings are similar to Goubert et al. [34] and higher than results reported by Huijer et al. [30] obtained in the context of the validation of another Arabic-language self-report measure. The RSMEA findings are similar to Huijer et al. [30] and Goubert et al. [34] but higher than other studies [21, 38, 39].

The factor structure of the PCS, whether assessed using exploratory or confirmatory FA approaches, has varied across studies. In the present study, the failure to replicate factor separation of the original Magnification and Rumination factors is not surprising given the known variation across investigations. It is important to note that the two-factor model obtained in the present study, Sullivan's original 3factor model, and the single-factor model based on the total score all provided very good fit to the data. As such, users of the PCS-A should feel comfortable scoring this measure according to Sullivan's original 3-factor item groupings and when using the total score, which is used most frequently in studies involving the PCS.

4.2. Reliability. Cronbach's alpha values in the present study were comparable to or exceeded values reported in previous studies $[1,21,22,37,38]$ suggesting a very high level of internal consistency. A similar pattern of findings was observed when examined in pain-free young adults. Taken together, these results suggest the PCS-A is reliable and compares well to the original version.

4.3. Validity. In Study 1, higher scores on catastrophizing were associated with higher levels of clinical pain severity and a greater degree of pain-related interference. Catastrophizing also showed a positive relationship to self-reported 
symptoms of depression and anxiety. This is consistent with previous studies showing a strong correlation between PCS, pain intensity, pain interference, depression, disability, emotional functioning, anxiety, physical functioning, and general health $[21,25,41]$. Regression analyses revealed that patient's responses on the PCS-A predicted decreases in general quality of life even after accounting for the significant contribution of demographic factors, pain severity, and depression.

In Study 2, increasing PCS-A scores were associated with heightened levels of experimental cold pressor pain, as suggested by lower pain thresholds, higher pain intensity ratings, and decreased pain tolerance. Furthermore, the pattern of the present findings is consistent with previous research suggesting that state catastrophizing (situation-specific thoughts) shows stronger and more consistent relationships with both clinical and experimental pain responsiveness compared to general measures of catastrophizing which rely on memory of past painful events $[5,42]$. Study 2 findings also suggest that the linguistic reach of the PCS-A extends beyond Lebanon and may be used to good effect with individuals in other Arab countries.

Overall, the present results provide strong support for the psychometric properties of the Arabic-language adaptation of the PCS-A. Although further research is needed to replicate and expand the current psychometric investigation, particularly among clinical pain groups in Arab-speaking countries outside of Lebanon, it is with confidence that we recommend the PCS-A for use by researchers and clinicians alike.

\section{Competing Interests}

The authors certify that they have no conflict of interests related to the publication of this manuscript. The authors certify that they have no direct financial involvement in any organization or entity that has a direct financial interest in the subject matter discussed in this manuscript.

\section{Acknowledgments}

The authors would like to extend their gratitude to Pfizer for funding this study and to Ms. Nadine Hamieh for her diligent work as research assistant on this project.

\section{References}

[1] M. J. L. Sullivan, S. R. Bishop, and J. Pivik, "The pain catastrophizing scale: development and validation," Psychological Assessment, vol. 7, no. 4, pp. 524-532, 1995.

[2] J. A. Turner and L. A. Aaron, "Pain-related catastrophizing: what is it?" Clinical Journal of Pain, vol. 17, no. 1, pp. 65-71, 2001.

[3] E. J. Bartley, J. L. Rhudy, and A. E. Williams, "Experimental assessment of affective processing in fibromyalgia," Journal of Pain, vol. 10, no. 11, pp. 1151-1160, 2009.

[4] D. J. French, M. Noël, F. Vigneau, J. A. French, P. Chantal, and R. T. Evans, "L'Échelle de dramatisation face à la douleur PCS-CF adaptation canadienne en langue française de l'échelle ńPain Catastrophizing Scależ," Canadian Journal of Behavioural Science, vol. 37, no. 3, pp. 181-192, 2005.
[5] J. L. Rhudy, L. J. Maynard, and J. L. Russell, "Does in vivo catastrophizing engage descending modulation of spinal nociception?" Journal of Pain, vol. 8, no. 4, pp. 325-333, 2007.

[6] M. J. L. Sullivan, W. M. Rodgers, P. M. Wilson, G. J. Bell, T. C. Murray, and S. N. Fraser, "An experimental investigation of the relation between catastrophizing and activity intolerance," Pain, vol. 100, no. 1-2, pp. 47-53, 2002.

[7] R. W. Butler, F. L. Damarin, C. Beaulieu, A. I. Schwebel, and B. E. Thorn, "Assessing cognitive coping strategies for acute postsurgical pain," Psychological Assessment, vol. 1, no. 1, pp. 41-45, 1989.

[8] J. A. Haythornthwaite, J. W. Lawrence, and J. A. Fauerbach, "Brief cognitive interventions for burn pain," Annals of Behavioral Medicine, vol. 23, no. 1, pp. 42-49, 2001.

[9] P. B. Jacobsen and R. W. Butler, "Relation of cognitive coping and catastrophizing to acute pain and analgesic use following breast cancer surgery," Journal of Behavioral Medicine, vol. 19, no. 1, pp. 17-29, 1996.

[10] M. J. L. Sullivan and N. Neish, "Catastrophizing, anxiety and pain during dental treatment," Community Dentistry and Oral Epidemiology, vol. 37, pp. 243-250, 1998.

[11] H. Flor, D. J. Behle, and N. Birbaumer, "Assessment of painrelated cognitions in chronic pain patients," Behaviour Research and Therapy, vol. 31, no. 1, pp. 63-73, 1993.

[12] F. J. Keefe, G. K. Brown, K. A. Wallston, and D. S. Caldwell, "Coping with rheumatoid arthritis pain: catastrophizing as a maladaptive strategy," Pain, vol. 37, no. 1, pp. 51-56, 1989.

[13] M. J. L. Sullivan and J. L. D’Eon, "Relation between catastrophizing and depression in chronic pain patients," Journal of Abnormal Psychology, vol. 99, no. 3, pp. 260-263, 1990.

[14] M. J. L. Sullivan, W. M. Rodgers, and I. Kirsch, "Catastrophizing, depression and expectancies for pain and emotional distress," Pain, vol. 91, no. 1-2, pp. 147-154, 2001.

[15] M. J. L. Sullivan, B. Thorn, J. A. Haythornthwaite et al., "Theoretical perspectives on the relation between catastrophizing and pain," The Clinical Journal of Pain, vol. 17, no. 1, pp. 52-64, 2001.

[16] T. Mankovsky, M. E. Lynch, A. J. Clark, J. Sawynok, and M. J. L. Sullivan, "Pain catastrophizing predicts poor response to topical analgesics in patients with neuropathic pain," Pain Research and Management, vol. 17, no. 1, pp. 10-14, 2012.

[17] M. Sullivan, M. Tanzer, W. Stanish et al., "Psychological determinants of problematic outcomes following Total Knee Arthroplasty," Pain, vol. 143, no. 1-2, pp. 123-129, 2009.

[18] T. H. Wideman and M. J. L. Sullivan, "Differential predictors of the long-term levels of pain intensity, work disability, healthcare use, and medication use in a sample of workers' compensation claimants," Pain, vol. 152, no. 2, pp. 376-383, 2011.

[19] M. J. L. Sullivan, "The communal coping model of pain catastrophising: clinical and research implications," Canadian Psychology, vol. 53, no. 1, pp. 32-41, 2012.

[20] M. J. L. Sullivan, L. C. Ward, D. Tripp, D. J. French, H. Adams, and W. D. Stanish, "Secondary prevention of work disability: community-based psychosocial intervention for musculoskeletal disorders," Journal of Occupational Rehabilitation, vol. 15, no. 3, pp. 377-392, 2005.

[21] K. Meyer, H. Sprott, and A. F. Mannion, "Cross-cultural adaptation, reliability, and validity of the German version of the Pain Catastrophizing Scale," Journal of Psychosomatic Research, vol. 64, no. 5, pp. 469-478, 2008.

[22] J. C. Yap, J. Lau, P. P. Chen et al., "Validation of the Chinese Pain Catastrophizing Scale (HK-PCS) in patients with chronic pain," Pain Medicine, vol. 9, no. 2, pp. 186-195, 2008. 
[23] F. Sehn, E. Chachamovich, L. P. Vidor et al., "Cross-cultural adaptation and validation of the Brazilian Portuguese version of the pain catastrophizing scale," Pain Medicine, vol. 13, no. 11, pp. 1425-1435, 2012.

[24] L. Fernandes, K. Storheim, I. Lochting, and M. Grotle, "Crosscultural adaptation and validation of the Norwegian pain catastrophizing scale in patients with low back pain," BMC Musculoskeletal Disorders, vol. 13, article 111, 2012.

[25] S. Cho, H.-Y. Kim, and J.-H. Lee, "Validation of the Korean version of the Pain Catastrophizing Scale in patients with chronic non-cancer pain," Quality of Life Research, vol. 22, no. 7, pp. 1767-1772, 2013.

[26] B. Kröner-Herwig and J. Maas, "The german pain catastrophizing scale for children (PCS-C) - psychometric analysis and evaluation of the construct," GMS Psycho-Social-Medicine, vol. 10, article Doc07, 2013.

[27] R. W. Pallegama, A. Ariyawardana, A. W. Ranasinghe et al., "The Sinhala version of the pain catastrophizing scale: validation and establishment of the factor structure in pain patients and healthy adults," Pain Medicine, vol. 15, no. 10, pp. 1734-1742, 2014.

[28] F. H. Mohd Din, V. C. W. Hoe, C. K. Chan, and M. A. Muslan, "Cultural adaptation and psychometric assessment of Pain Catastrophizing Scale among young healthy Malay-speaking adults in military settings," Quality of Life Research, vol. 24, no. 5, pp. 1275-1280, 2015.

[29] S. Ballout, S. Noureddine, H. A.-S. Huijer, and G. Kanazi, "Psychometric evaluation of the arabic brief pain inventory in a sample of lebanese cancer patients," Journal of Pain and Symptom Management, vol. 42, no. 1, pp. 147-154, 2011.

[30] H. A.-S. Huijer, K. Sagherian, and H. Tamim, "Validation of the Arabic version of the EORTC quality of life questionnaire among cancer patients in Lebanon," Quality of Life Research, vol. 22, no. 6, pp. 1473-1481, 2013.

[31] R. A. Lopes, R. C. Dias, B. Z. de Queiroz et al., "Psychometric properties of the Brazilian version of the pain catastrophizing scale for acute low back pain," Arquivos de Neuro-Psiquiatria, vol. 73, no. 5, pp. 436-444, 2015.

[32] S. S. Kazarian and D. Taher, "Validation of the Arabic Center for Epidemiological Studies Depression (CES-D) scale in a lebanese community sample," European Journal of Psychological Assessment, vol. 26, no. 1, pp. 68-73, 2010.

[33] A. Cano, M. T. Leonard, and A. Franz, "The significant other version of the Pain Catastrophizing Scale (PCS-S): preliminary validation," Pain, vol. 119, no. 1-3, pp. 26-37, 2005.

[34] L. Goubert, C. Eccleston, T. Vervoort, A. Jordan, and G. Crombez, "Parental catastrophizing about their child's pain. The parent version of the Pain Catastrophizing Scale (PCS-P): a preliminary validation," Pain, vol. 123, no. 3, pp. 254-263, 2006.

[35] C. D. Spielberger, Manual for the State-Trait Anxiety Inventory (form Y), Consulting Psychologist Press, Palo Alto, Calif, USA, 1983.

[36] M. P. Jensen and P. Karoly, "Self-report sale and procedures for assessing pain in adults," in Handbook of Pain Assessment, D. C. Turk and R. Melzack, Eds., pp. 15-34, The Guilford Press, New York, NY, USA, 2001.

[37] A. Osman, F. X. Barrios, P. M. Gutierrez, B. A. Kopper, T. Merrifield, and L. Grittmann, "The pain catastrophizing scale: further psychometric evaluation with adult samples," Journal of Behavioral Medicine, vol. 23, no. 4, pp. 351-365, 2000.
[38] G. Crombez, P. Bijttebier, C. Eccleston et al., "The child version of the pain catastrophizing scale (PCS-C): a preliminary validation," Pain, vol. 104, no. 3, pp. 639-646, 2003.

[39] J. L. D’Eon, C. A. Harris, and J. A. Ellis, “Testing factorial validity and gender invariance of the pain catastrophizing scale," Journal of Behavioral Medicine, vol. 27, no. 4, pp. 361-372, 2004.

[40] S. Van Damme, G. Crombez, P. Bijttebier, L. Goubert, and B. Van Houdenhove, "A confirmatory factor analysis of the Pain Catastrophizing Scale: invariant factor structure across clinical and non-clinical populations," Pain, vol. 96, no. 3, pp. 319-324, 2002.

[41] J. Miró, R. Nieto, and A. Huguet, "The Catalan version of the Pain Catastrophizing Scale: a useful instrument to assess catastrophic thinking in whiplash patients," Journal of Pain, vol. 9, no. 5, pp. 397-406, 2008.

[42] J. A. Sturgeon and A. J. Zautra, "State and trait pain catastrophizing and emotional health in rheumatoid arthritis," Annals of Behavioral Medicine, vol. 45, no. 1, pp. 69-77, 2013. 


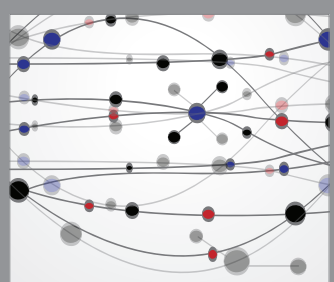

The Scientific World Journal
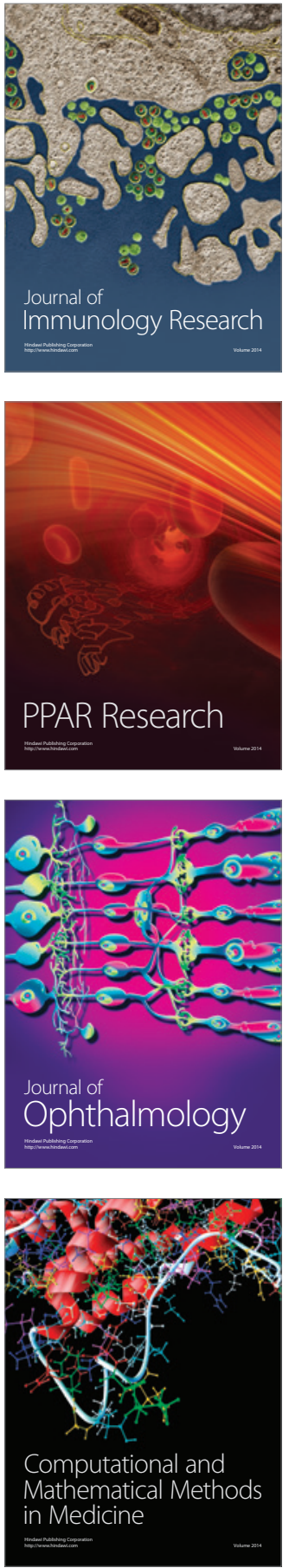

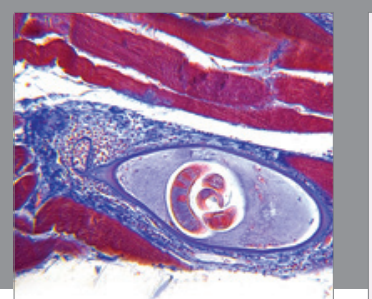

Gastroenterology Research and Practice
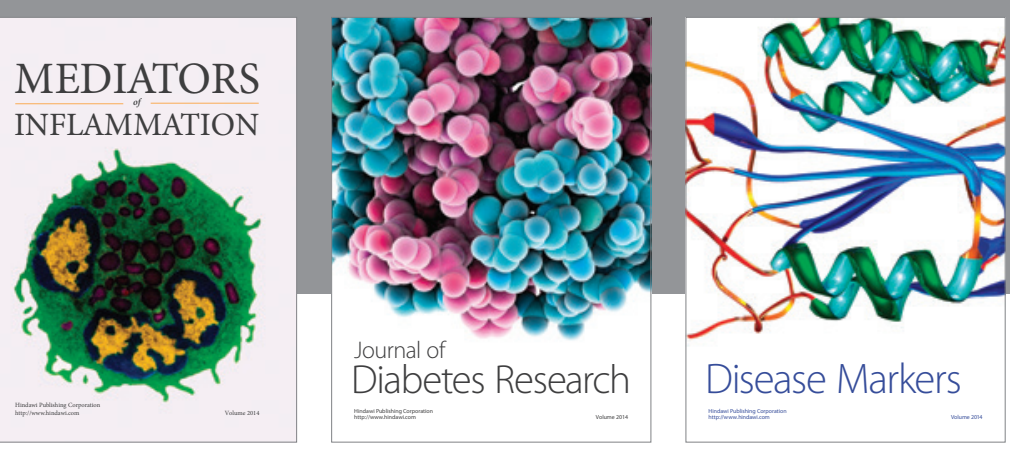

Disease Markers

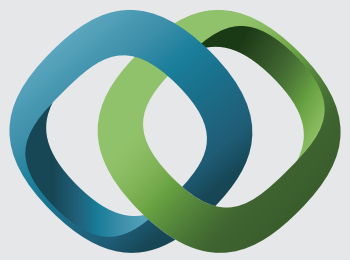

\section{Hindawi}

Submit your manuscripts at

https://www.hindawi.com
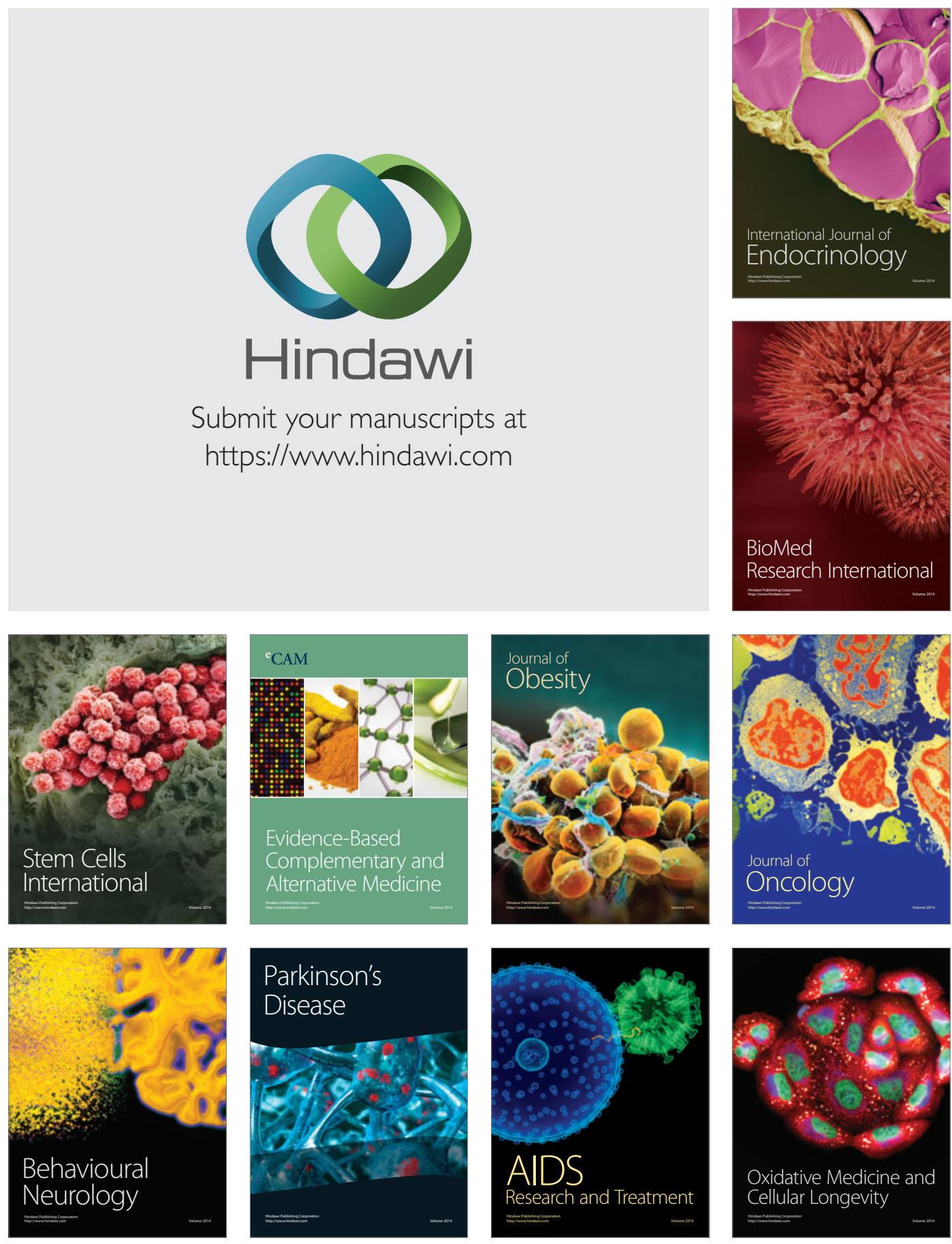